\title{
Back to black bag and horse-and-buggy medicine
}

$\mathrm{T}$ he case for house calls is compelling, particularly in an era in which treatment of chronic diseases is consuming more of the health care dollar and more senior citizens need care. But financial incentives for physicians to return to black bag and horse-and-buggy medicine haven't followed suit.

"The majority of family doctors don't make home visits. So these seniors sort of slip through the cracks until there's a crisis and they end up in the emergency department," says Dr. Mark Nowaczynski, a mobile physician who leads a provincially funded team in Toronto, Ontario, that makes house calls. Their "needs are not being well met by our office-based, primary care model of delivery."

Seniors across the country are often released from hospital with no access to a family physician, he says. "It's happening over and over again in every hospital in the country on a daily basis."

"Our population is rapidly aging and the number of Canadians over the age of 85 is now the fastest growing segment of the population and if we don't deliver care in a more targeted way to this population, we're simply going to continue to have these people come through hospitals, like coming through a revolving door," Nowaczynski says.

But College of Family Physicians of Canada President Dr. Robert Boulay argues that Canadian physicians are already making the shift back toward house calls.

There's been an upward trend in the frequency of house calls as physicians move toward "patient-centred care" and their patient pools age, he says. Results from the 2010 National Physician Survey indicate that "as physicians got older they were doing more house calls and I think that's probably a reflection of the relationship aspect of our work so as you establish more of a relationship with people and follow them for a longer time, most of us would transition to doing house calls for them as they become more disabled or have terminal illnesses.'

The survey numbers, though, don't entirely support that proposition. The 2010 numbers - $42.4 \%$ of 6337 family and general physicians - are slightly lower than the $48.3 \%$ of 9930 physicians who indicated that they visited patients in their homes in 2007 (www.nationalphysiciansurvey.ca/nps/ 2010_Survey/Results/pdf/en/national /Q15/Q15i_FP.pdf).

But Boulay says the survey did not inquire as to the number of house calls a physician made, so while the percentage of doctors making house calls seems lower, the overall number of visits has likely increased.

Dr. John Sloan, a family physician in Vancouver, British Columbia who has been making house calls for 15 years, concurs. "There's the usually cited idea that the doctor with the black bag and the horse and buggy is now returning and it's not so much about that as it is about a better way of meeting the needs of a group of patients that we refer to as frail," he says.

Whether or not house calls are actually on the rise, they'll have to be in the

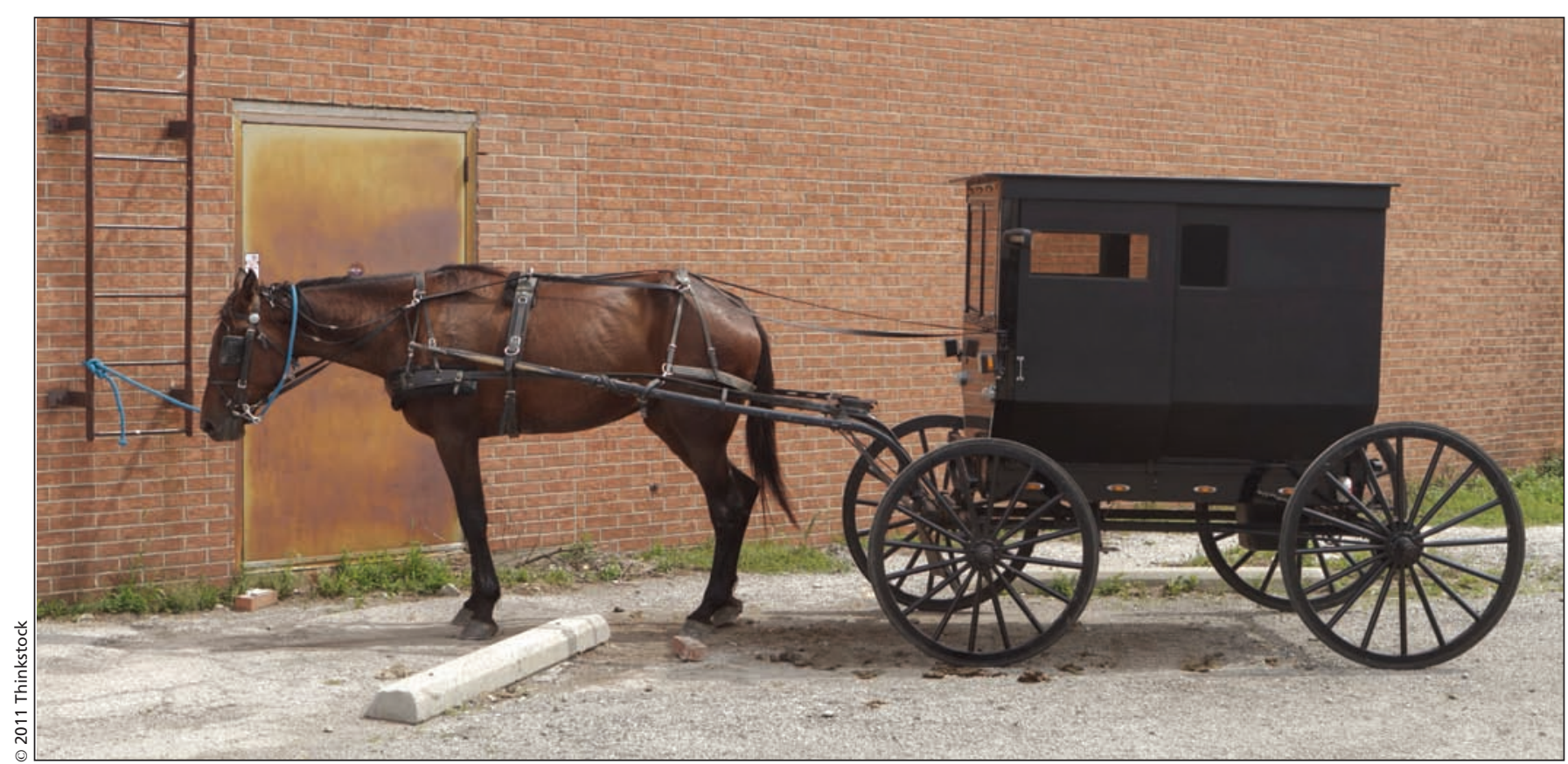

"There's the usually cited idea that the doctor with the black bag and the horse and buggy is now returning and it's not so much about that as it is about a better way of meeting the needs of a group of patients that we refer to as frail," says Dr. John Sloan, a family physician in Vancouver, British Columbia. 
future, and financial incentives will have to follow suit, the physicians argue.

"We prevent many hospital admissions, we prevent hospital readmissions and we delay and prevent admissions to long-term care and all of those things are hugely expensive," says Nowaczynski, head of a provincially funded House Calls team that includes a nurse practitioner, an occupational therapist, social worker and team coordinator.

The team's annual budget is $\$ 480000$ and in 22 months of operation, they've assessed nearly 400 patients. The average hospital admission for a frail senior costs the Ontario government $\$ 7000$ to $\$ 10$ 000, and a government subsidy for a bed in a long-term care facility is roughly $\$ 40$ 000, Nowaczynski says. So the province's investment is saved "many times on an annual basis."

If it keeps patients out of acute care facilities, it's to everyone's advantage, says Hugh MacLeod, chief executive officer of the Canadian Patient Safety Institute. "If we improve the game here, not only does the individual benefit, but the system benefits and you don't place that individual in a place of sickness called a hospital and that should be our goal. Reduce the amount of traffic that goes to a hospital."
Payment models, though, do little to encourage house calls.

In fact, in Ontario, funding of the health care system has even worked to disadvantage house calls, Nowaczynski says, explaining that during the 1990s, the government shifted threequarters of the home and chronic care budget to acute care, so that hospitals could discharge patients quicker. "I saw a lot of my housebound patients lose services."

"There are not the right financial incentives for family physicians to make home visits so physicians do it as almost an afterthought or an add-on to a busy office-based practice and the incentives are far greater to practise medicine in an office-based setting," he adds.

British Columbia is the only province that has raised payments to physicians for house calls, to $\$ 108$ per visit, Sloan notes. That's a reasonable fee "when consider that if you do this major, major part-time or full-time, you lose a big chunk of overhead" costs related to running an office, he says. "You make more money in British Columbia if you see more people at home."

Nowaczynski argues that $5 \%$ of hospital funding should be funnelled into home-based care. "We would decrease hospital utilization and hospitals wouldn't miss the decrease in their budgets."

Such a shift would "have to be mandated," he adds. "We need strong government leadership and policy to look at more effective ways of delivering care to frail seniors because our current system is rapidly getting into trouble."

But as Sloan notes, summoning the "political will" to make major changes in the funding of health care is "not easy to do."

Nowaczynski believes the answer might lie in something as simple as having everyone do their part. "I think the solution is to have a lot more family physicians doing a little bit of homebased care. That would have a greater system-wide impact."

That cause might be abetted by the findings of a \$1 million, two-year Canadian Patient Safety Institute study that is examining the safety and efficacy of home care (www.patientsafety institute.ca/English/news/newsReleases /Documents/1\%20million\%20dollars\% 20awarded $\% 20$ to $\% 20$ identify $\% 20$ safety $\% 20$ risks \%20with\%20care\%20in $\% 20$ homes.pdf). - Erin Walkinshaw, Ottawa, Ont.

CMAJ 2011. DOI:10.1503/cmaj.109-3995

\section{Mandatory vaccinations: No middle ground}

$\mathrm{F}$ ew issues generate such impassioned debate as mandatory vaccination policies. Advocates say vaccines are safe and exemptions should be minimal. Opponents counter that vaccines are hazardous to health and that any limitation on exemptions is a violation of constitutional rights.

"Immunizations are the safest, longest-lasting and most effective way to prevent communicable diseases," says Dr. Ian Gemmill, past chair of the Canadian Coalition of Immunization Awareness and Promotion, a nongovernmental advocacy organization.

Vaccines were responsible for stopping meningococcal disease outbreaks in the 1990s and early 2000s, and more recently, helped end the influenza pandemic in 2009, Gemmill says. "You could argue it was going to end anyways, but I think that the immunization program certainly blunted the final effects of the pandemic."

The numbers speak for themselves, he adds. In the case of measles, prior to the development of a vaccine, there were about 300000 cases per year among Canadian children under the age of 18. Of those, about 300 died annually, while about 300 were left with brain damage (http://gnb.ca/0053/public _health/pdf/2011/parent-guide-to-immu nization_april2011-e.pdf). Now there are less than 50 cases per year and no deaths, Gemmill says. Similarly, the incidence of pertussis dropped from 30000 to 50000 cases, and 50 to 100 deaths, per year, to just 3000 and 1 to 5 deaths following the development of a vaccine.
The numbers suggest that mandatory immunization policies are appropriate in certain environments, says Gemmill. "There are some circumstances, like schoolchildren [and] for sure, health care workers, where there are compelling arguments that can be made and should be respected around requiring people to be immunized. But it's not true for every single vaccine and every single circumstance."

Anyone who works in a health care facility should be required to be vaccinated on the grounds that they are in a position to put vulnerable people at risk and could be "knocked out" during a pandemic, he adds. "If you have enough people out then you're actually jeopardizing your health system just when people need it the most." 